\title{
PENGEMBANGAN APLIKASI PENJADWALAN KEGIATAN PELATIHAN TEKNOLOGI INFORMASI DAN KOMUNIKASI DENGAN ALGORITMA GENETIKA (STUDI KASUS: BPRTIK)
}

\author{
Restie Maya Puspita ${ }^{1}$, Arini ${ }^{2}$, Siti Ummi Masrurah ${ }^{3}$ \\ ${ }^{1,2,3}$ Program Studi Teknik Informatika \\ Fakultas Sains dan Teknologi \\ Universitas Islam Negeri Syarif Hidayatullah Jakarta \\ e- restiemaya@gmail.com, ${ }^{2}$ arini@uinjkt.ac.id
}

\begin{abstract}
Abstrak - Penelitian ini bertujuan untuk mengembangkan aplikasi yang dapat mengoptimalkan penjadwalan kegiatan di Balai Pelatihan Riset Teknologi Informasi dan Komunikasi (BPRTIK), Ciputat, Tangerang Selatan dengan mengimplementasikan Algoritma Genetika (AG). Penulis memahami bahwa proses kegiatan yang diatur secara manual belum dapat dilakukan secara optimal sehingga perlu adanya revisi rancangan kegiatan yang dikelola secara maksimal melalui penggunaan aplikasi optimasi penjadwalan yang terstruktur secara otomatis. Oleh sebab itu, kebutuhan terhadap optimasi penjadwalan menjadi penting dan pembuatan aplikasi pada bidang tersebut harus dibangun secara komperhensif. Algoritma Genetika menawarkan metode komperhensif dalam pengolahan data optimal dengan mengadopsi konsep seleksi alam sebagai tolak ukur dalam pemilihan dan penentuan data yang diperlukan. Di samping itu, untuk mengembangkan dan mengukur $A G$, penulis juga menerapkan metodologi Rapid Application Development (RAD) yang mencakup fase perencanaan, desain perancangan, dan fase pelaksanaan dalam proses pengembangan sistem aplikasi yang selanjutnya dikembangkan dengan PHP dan MySQL sebagai platform utama dan Adobe Dreamweaver CS6 dan Microsoft Visio 2007 sebagai infrastruktur grafis. Sebagai kesimpulan, penulis menemukan bahwa implementasi Algoritma Genetika pada aplikasi optimasi penjadwalan kegiatan menghasilkan kinerja yang lebih optimal pada proses pemilihan dan pengolahan data pada aplikasi yang telah dikelola sehingga menghasilkan produk penjadwalan yang lebih terstruktur.
\end{abstract}

Kata Kunci: Optimasi Penjadwalan Kegiatan, Algoritma Genetika, PHP

\section{PENDAHULUAN}

A. Latar Belakang

Balai Pelatihan Riset Teknologi Informasi dan Komunikasi (BPRTIK) merupakan pusat pelatihan teknologi informasi yang dibangun oleh pemerintah guna menjawab tantangan globalisasi maupun kesenjangan digital yang terjadi di negeri ini.

Sesuai dengan tujuan dibangunnya BPRTIK yaitu meningkatkan kualitas sarana dan prasarana pengembangan sumber daya manusia teknologi informasi dan komunikasi serta meningkatkan kesejahteraan dan pemberdayaan masyarakat pengguna teknologi informasi dan komunikasi, maka terdapat pelatihan yang akan dihadiri oleh peserta dan pengajar.

Berdasarkan hasil wawancara kegiatan yang diadakan di BPRTIK memerlukan penjadwalan kegiatan agar kegiatan berjalan sesuai dengan yang telah direncanakan. Proses pembuatan jadwal kegiatan akan menjadi sangat rumit ketika masih dilakukan secara manual, karena data yang dihasilkan cenderung tidak berkualitas baik. Masalah ini membutuhkan waktu komputasi yang cukup tinggi untuk pencarian solusinya, terlebih jika ukuran permasalahan semakin besar dengan bertambahnya jumlah komponen dan tetapan atau syarat yang ditentukan oleh institusi tempat jadwal tersebut digunakan.

Tujuan penjadwalan adalah cara mengatur sejumlah komponen sesuai dengan tetapan dan syarat tertentu dalam satu waktu. Dalam penjadwalan kegiatan ini komponen yang dimaksud adalah penangung jawab, kegiatan, dan ruangan. Jika pengalokasian dari komponen-komponen tersebut tidak dilakukan dengan baik, maka akan mengakibatkan penumpukkan jadwal pada tempat dan waktu tertentu.

Dengan kemajuan ilmu pengetahuan dalam bidang komputer, masalah penjadwalan di atas dapat dioptimasi menggunakan metode algoritma genetika yang memberikan solusi optimal sesuai dengan batasan dan syarat yang sudah ditentukan.

Algoritma genetika pertama kali diperkenalkan sekitar tahun 1975 oleh John Holland dalam bukunya yang berjudul "Adaption in Natural and Artificial Systems" dan kemudian dikembangkan bersama murid dan rekan kerjanya (John Holland, 1992).

Algoritma genetika sebagai cabang dari algoritma evolusi merupakan metode adaptif yang bisa digunakan untuk memecahkan suatu pencarian nilai dalam sebuah masalah optimasi (E. Satriyanto, 2009). Algoritma ini didasarkan pada proses genetik yang ada dalam bentuk makhluk hidup, yaitu perkembangan generasi dalam sebuah populasi yang alami, secara lambat laun mengikuti prinsip seleksi alam. Dengan meniru teori evousi ini, algoritma 
genetika dapat digunakan untuk mencari solusi permasalahan-permasalahan dalam dunia nyata yang optimal dan efektif.

\section{B. Metodologi Penelitian}

a. Metode Pengumpulan Data

Metode pengumpulan data yang digunakan dalam penelitian ini terdiri dari dua jenis, yaitu metode studi lapangan dan studi literatur. Metode studi lapangan menggunakan metode observasi dan wawancara.

b. Metode Pengembangan Sistem

Penulis menggunakan metode pengembangan sistem dengan metode Rapid Application Development (RAD).

\section{LANDASAN TEORI}

A. Implementasi

Secara sederhana implementasi bisa diartikan pelaksanaan atau penerapan. Majone dan Wildavsky (Usman, 2002), mengemukakan implementasi sebagai evaluasi. Browne dan Wildavsky mengemukakan bahwa "implementasi adalah perluasan aktivitas yang saling menyesuaikan". Pengertian implementasi sebagai aktivitas yang saling menyesuaikan juga dikemukakan oleh Mclaughin. Adapun Schubert mengemukakan bahwa "implementasi adalah sistem rekayasa".

\section{B. Aplikasi}

Istilah aplikasi berasal dari bahasa inggris application yang berarti penerapan, lamaran ataupun penggunaan. Aplikasi adalah software yang dibuat oleh suatu perusahaan komputer untuk mengerjakan tugastugas tertentu, misalnya Microsoft Word, Microsoft Excel dan lain-lain (Dhanta, 2009).

\section{a. Optimasi}

Optimasi untuk memaksimalkan atau mengoptimalkan sesuatu hal yang bertujuan untuk mengelola sesuatu yang dikerjakan, sehingga optimasi bisa dikatakan kata benda yang berasal dari kata kerja dan optimasi bisa dianggap baik sebagai ilmu pengetahuan dan seni menurut tujuan yang ingin dimaksimalkan.

b. Penjadwalan

Penjadwalan adalah pengaturan waktu dari suatu kegiatan operasi penjadwalan yang mencakup kegiatan mengalokasikan fasilitas, peralatan atau tenaga kerja bagi suatu kegiatan operasi dan menentukan urutan pelaksanaan kegiatan operasi. Dalam hierarki pengambilan keputusan, penjadwalan merupakan langkah terakhir sebelum dimulainya operasi (Herjanto, 2001).

C. Algoritma Genetika

Algoritma genetika sebagai cabang dari algoritma evolusi merupakan metode adaptif yang bisa digunakan untuk memecahkan suatu pencarian nilai dalam sebuah masalah optimasi (Satriyanto, 2009)..

Menurut Goldberg mendefinisikan algoritma genetika ini sebagai suatu pencarian algoritma berdasarkan pada mekanisme seleksi alam dan genetika alam (Goldberg, 1989). Menurut Bauer mendefinisikan algoritma genetika sebagai perangkat lunak, prosedur yang dimodelkan setelah genetika dan evolusi (Bauer, 1993). Ada tiga keuntungan utama dalam mengaplikasikan algoritma genetika pada masalah-masalah optimasi (Widodo, 2012)

a. Struktur Umum Algoritma Genetika

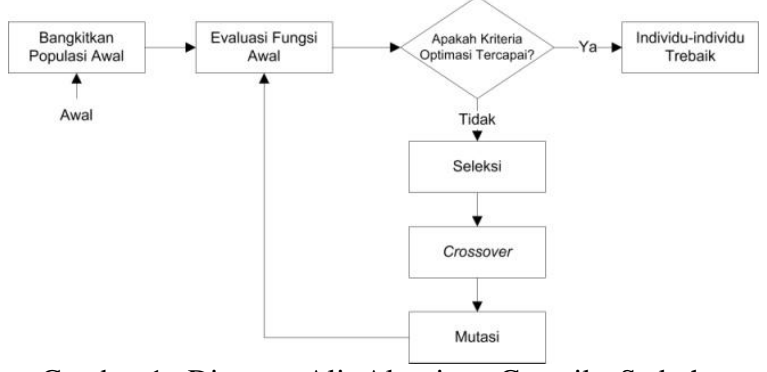

Gambar 1. Diagram Alir Algoritma Genetika Sederhana

b. Komponen Utama Algoritma Genetika

Terdapat enam komponen utama dalam algoritma genetika (Kusumadewi, 2003), yaitu Teknik Penyandian, Prosedur Inisialisasi, Fungsi Evaluasi, Seleksi, Operator Genetika dan Penentuan Parameter.

\section{METODOLOGI PENELITIAN}

\section{A. Perangkat Penelitian}

a. Perangkat Keras (Hardware)

Perangkat keras yang digunakan pada penelitian ini adalah sebuah laptop Toshiba Satellite L740 dengan spesifikasi operation systems Windows 7, processor Intel Core i3 M $380 @ 2.53$ Ghz, RAM 2.00 GB, dan 64-bit Operating System.

b. Perangkat Lunak (Software)

Perangkat lunak yang digunakan pada penilitian ini adalah Adobe Dreamweaver CS6, XAMPP, MySQL, NovaPDF, dan Microsoft Visio 2007.

B. Metode Pengumpulan Data

a. Data Primer

1) Observasi (Pengamatan)

Pengamatan penelitian ini dilaksanakan di bulan September 2014 dan bertempat di BPRTIK.

2) Wawancara

Pada metode ini, dilakukan tanggal 24 September 2014 dengan Tita sebagai admin yang bertugas membuat rancangan kegiatan dalam jangka waktu panjang dan dengan Bpk. Karma selaku staf data center.

b. Data Sekunder

Mencari dan mendapatkan informasi atau data yang diperoleh dari buku-buku, literatur sejenis, internet maupun sumber-sumber lainnya sesuai dengan masalah yang diangkat.

\section{Metode Pengembangan Sistem}

Dalam pengembangan sistem penjadwalan kegiatan ini, penulis menggunakan model Rapid Application Development (RAD). Model RAD dipilih karena tahapan-tahapan yang sangat terstruktur, dapat dilakukan dalam waktu yang cepat dan aplikasi akan 
menjadi sistem fungsional yang utuh, karena pengguna dilibatkan secara langsung.

\section{ANALISIS DAN PEMBAHASAN}

A. Fase Perencanaan Syarat-syarat

a. Tujuan Sistem

Membantu Admin Kegiatan BPRTIK dalam mengolah data dan mencari solusi terbaik untuk menentukan jadwal kegiatan agar tidak bersinggungan.

b. Syarat-syarat Informasi

Kelengkapan data, software, dan hardware. Kelengkapan data yang digunakan untuk pengembangan sistem penjadwalan kegiatan tersebut yaitu: Data penanggung jawab, Data penyelenggara, Data peserta, Data ruangan, dan Data kegiatan

c. Analisa Kebutuhan Sistem

Admin kegiatan BPRTIK selama ini menggunakan Microsot Excel dalam proses pembuatan jadwal kegiatan secara manual. Sehingga dibutuhkan ketelitian yang tinggi dan waktu yang cukup lama dalam pembuatan jadwal kegiatan, karena dipengaruhi oleh banyaknya jumlah penanggung jawab, kegiatan-kegiatan, dan ruang.

d. Sistem Penjadwalan yang Berjalan

Dalam mengolah data kegiatan, BPRTIK memiliki prosedur yang berlaku dalam pembuatan jadwal kegiatan, yaitu:

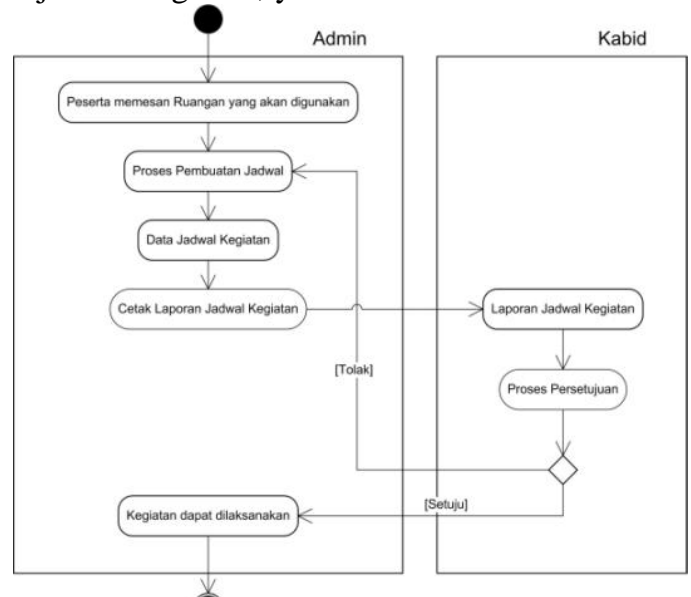

Gambar 2. Activity Diagram Sistem Penjadwalan yang Berjalan

e. Alternatif Penyelesaian Masalah

Implementasi algoritma genetika dalam aplikasi optimasi penjadwalan kegiatan menjadi usulan solusi untuk permasalahan yang ada.

f. Sistem Penjadwalan yang Diusulkan

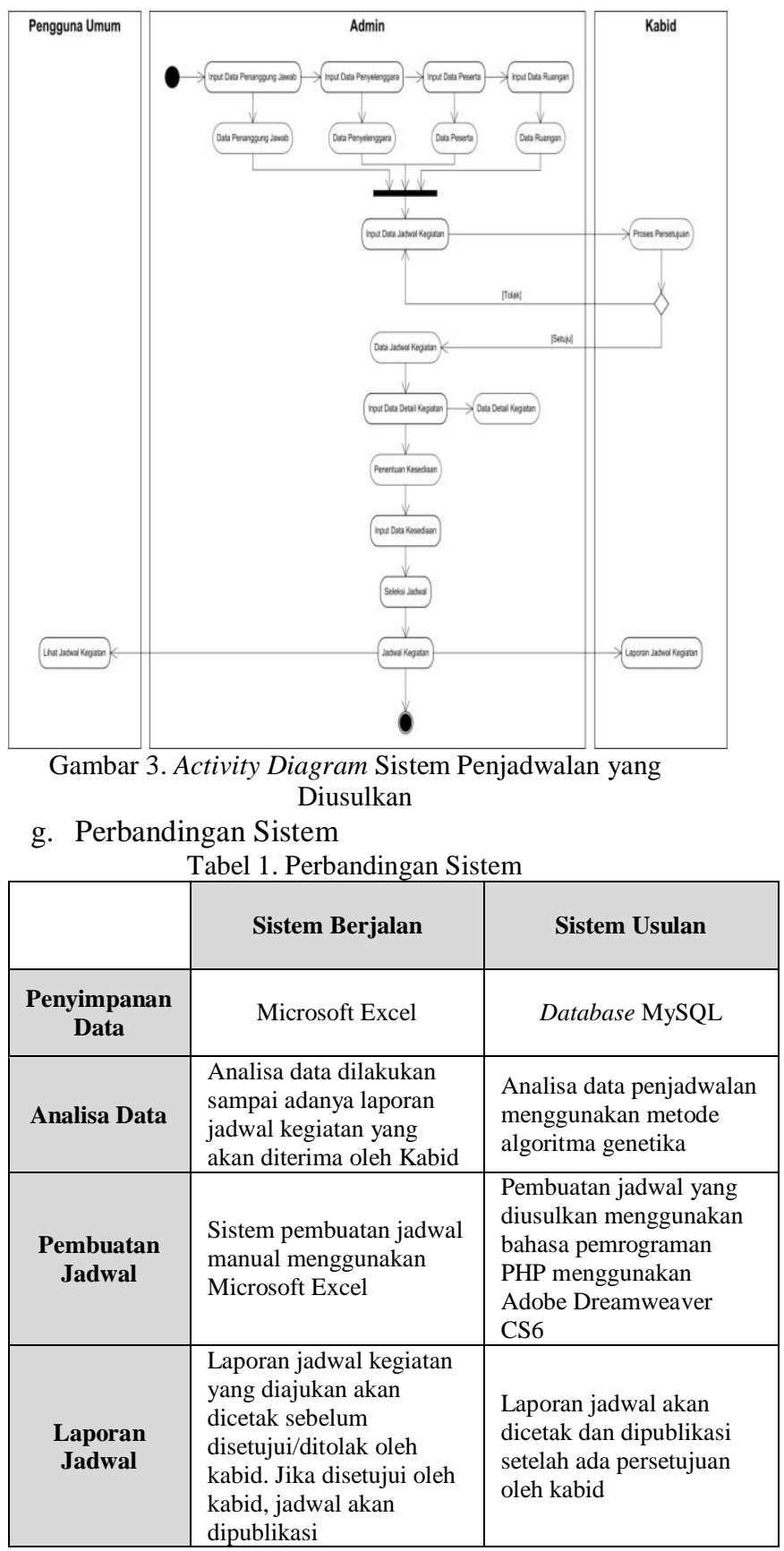

B. Workshop Design

a. Desain Sistem Algoritma Genetika

Menentukan pembangkitan populasi awal, teknik penyandian, melakukan fungsi fitness, menentukan prosedur inisialisasi, evaluasi, kriteria optimasi tercapai, seleksi, crossover (penyilangan), mutasi, dan penentuan generasi terakhir.

b. Perancangan Proses

1) Use Case Diagram

Terdapat tiga actor yang berinteraksi dengan sistem, yaitu: Admin, Kabid dan User.

2) Activity Diagram

Activity diagram menggambarkan aliran fungsionalitas dalam suatu sistem dapat digunakan 
dalam analisa kebutuhan untuk menggambarkan aliran kejadian melalui suatu use case.

\section{3) Sequence Diagram}

Sequence diagram menjelaskan secara detail urutan proses atau pesan yang dilakukan dalam sistem untuk mencapai tujuan dari use case, dimana proses atau pesan ini merupakan event atau metode dari objek ke class.

\section{4) Class Diagram}

Class diagram menjelaskan desain sistem yang akan dibangun. Setiap class akan diwakili oleh tabel, attribute class yang akan menjadi field dalam tabel.

c. Perancangan Antarmuka

1) Home

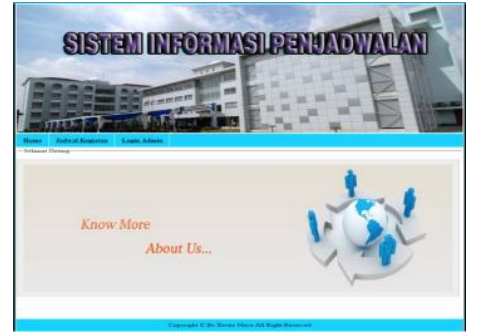

Gambar 4. Halaman Utama Web

2) Halaman Jadwal Kegiatan

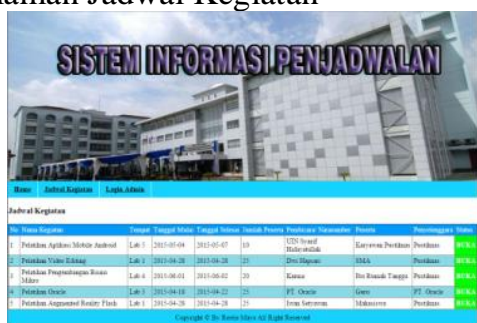

Gambar 5. Halaman Jadwal Kegiatan

3) Form Login

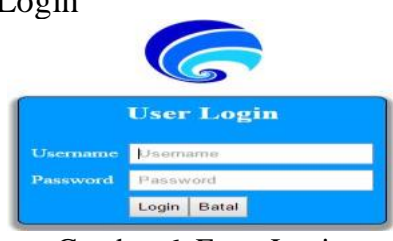

4) Menu Utama

Gambar 6. Form Login

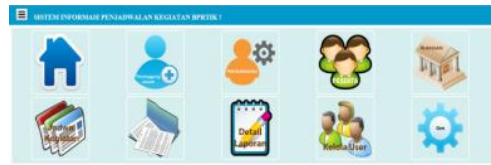

Gambar 7. Halaman Menu Utama Admin

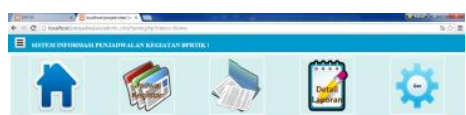

Gambar 8. Halaman Menu Utama Kabid

5) Halaman Menu Penanggung Jawab

Admin dapat merubah dengan menekan tombol edit dan menghapus data penanggung jawab dengan menekan tombol hapus.

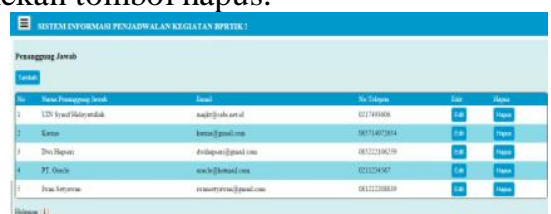

Gambar 9. Halaman Penanggung Jawab

6) Form Data Penanggung Jawab

Admin dapat menambah data penanggung jawab dengan mengisi form penanggung jawab.

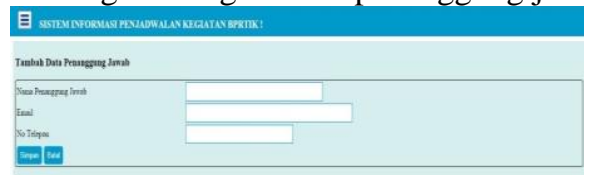

Gambar 10. Tambah (Form) Penanggung Jawab

7) Halaman Menu Jadwal Kegiatan (Admin)

Admin dapat mengolah data jadwal kegiatan yang akan dilaksanakan di BPRTIK.

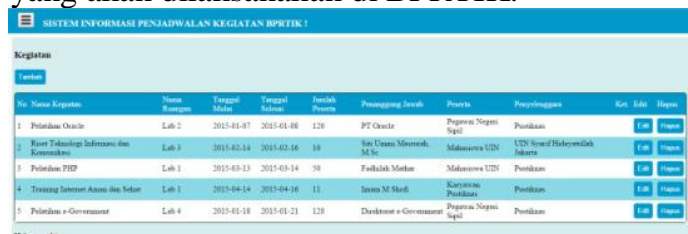

Gambar 11. Halaman Menu Jadwal Kegiatan (Admin)

8) Form Data Jadwal Kegiatan

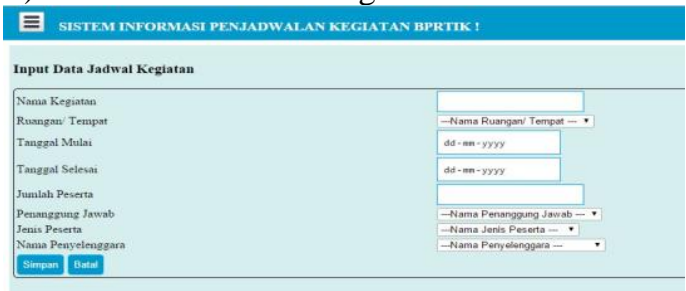

Gambar 12. Tambah (Form) Kegiatan

9) Halaman Menu Kegiatan (Kabid)

Kabid tidak dapat merubah data, tapi kabid dapat menyetujui kegiatan yang diajukan dengan menekan tombol approve atau menolak kegiatan tersebut dengan menekan tombol tolak.

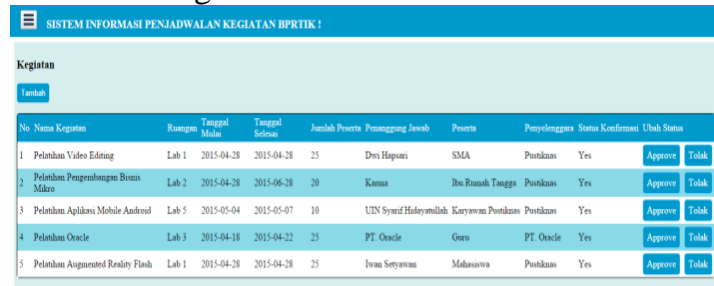

Gambar 13. Halaman Menu Jadwal Kegiatan (Kabid)

10) Halaman Menu Laporan 
Admin dan Kabid dapat melihat laporan jadwal kegiatan yang akan/telah dilaksanakan di BPRTIK.
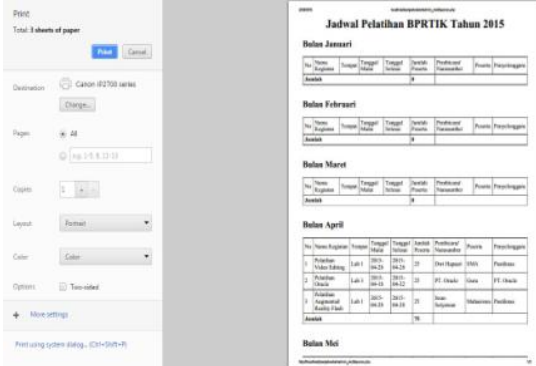

Gambar 14. Halaman Menu Laporan

11) Halaman Menu Kelola User

Admin dapat mengelola pengguna sistem aplikasi penjadwalan kegiatan.

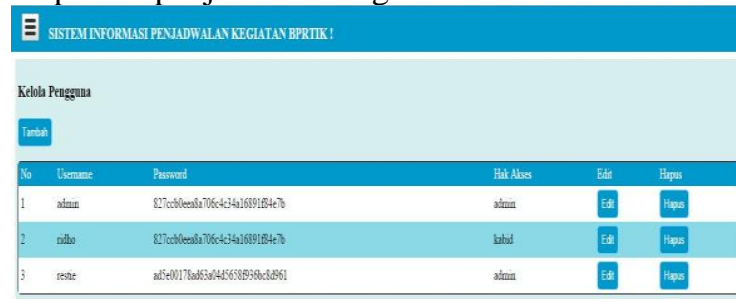

Gambar 15. Halaman Menu Kelola User

12)Form User

Admin dapat menambah data user sesuai hak akses (pilih salah satu).

\section{E SISIEMINTORMAST PENJADWALAN KEGAATAN BPRTIK!}

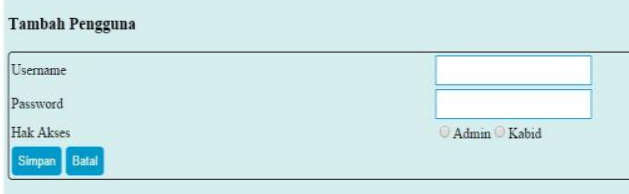

Gambar 16. Tambah (Form) User

\section{Fase Pelaksanaan}

a. Perangkat Keras

Perangkat yang dibutuhkan untuk pengujian aplikasi adalah Personal Computer (PC) atau laptop, dan printer.

b. Pengujian Sistem

Pada pengujian sistem, penulis melakukan testing terhadap sistem penjadwalan kegiatan ini dengan menggunakan pengujian tampilan dan pengujian blackbox.

\section{PENUTUP}

A. Kesimpulan

- Metode algoritma genetika dapat digunakan dalam pengembangan aplikasi yang dapat memberikan solusi untuk masalah penjadwalan kegiatan dengan menghasilkan suatu jadwal kegiatan yang optimal

- Penggunaan metode algoritma genetika dalam aplikasi pembuatan jadwal kegiatan dapat memberikan kemudahan dalam proses penjadwalan.

- Suatu jadwal dapat dikatakan optimal apabila dalam proses pengolahan data jadwal memberikan solusi efisiensi baik dari segi waktu, tenaga, dan sumber daya lainnya, dan tidak terjadi jadwal yang bersinggungan dalam ruangan yang sama.

5.1. Saran

- Untuk memperoleh hasil yang lebih baik dalam pencarian solusi dapat menggunakan jenis-jenis operator algoritma genetika lainnya.

- Pengembangan aplikasi berikutnya dapat menggunakan bahasa pemrograman lain dengan tampilan yang lebih menarik.

\section{REFERENSI}

Andika, F. (11 September 2014). Kelebihan, Kelemahan, dan Aplikasi 10 Bahasa Pemrograman. Diakses dari https://andikafisma.wordpress.com/kelebihankelemahan-dan-aplikasi-10-bahasapemrograman/

Anisyah. (2000). Analisa dan Desain Sistem Informasi. Yogyakarta: Andi

Bentley, L. D., dan Whitten, J. L. (2007). Systems Analysis and Design for the Global Enterprise $\left(7^{\text {th }}\right.$ Ed), International Edition. New York: McGrawHill

Dhanta, R. (2009). Pengantar Ilmu Komputer. Surabaya: Indah

Fowler, M. (2003). UML Distilled: A Brief Guide to the Standard Object (3th Ed). Addison-Wesley Professional

Gulo, W. (2002). Metode Penelitian. Jakarta: PT. Grasindo

Hasan, I. (2004). Metode Penelitian. Jakarta: Bumi Aksara

Herjanto, E. (2001). Manajemen Operasi (Edisi Ketiga). Jakarta: Grasindo

Hermawan, J. (2004). Analisis Desain dan Pemrograman Berorientasi Objek dengan UML dan Visual Basic.NET (Edisi Pertama). Yogyakarta: Andi Offset

Holland, J. H. (1992). Adaption in Natural and Artifial Systems: An Introducy Analysis with Applications to Biology, Control, and Artificial Intelligence. MIT Press

Jogiyanto. (2005). Analisis dan Desain Sistem Informasi. Yogyakarta: Penerbit Andi.

Kendall, K. E., dan J. E. Kendall. (2006). Analisis dan Perancangan Sistem (Edisi Keempat). Bandung: PT Index

Komputer, W. (2010). Tips Jitu Optimalisasi Jaringan Wi-Fi (Edisi Pertama). Yogyakarta: C.V. Andi Offset

Kustiyaningsih, Y., dan Anamisa, D. R. (2011). Pemrograman Basis Data Berbasis Web Menggunakan PHP\& MySQL (Edisi Pertama). Yogyakarta: Graha Ilmu.

Kusumadewi, S. (2003). Artificial Intelligence (Teknik dan Aplikasinya). Yogyakarta: Graha Ilmu

Ladjamudin. (2005). Analisis dan Desain Sistem Informasi. Yogyakarta: Graha Ilmu 
Nazir, M. (1998). Metode Penelitian. Jakarta: Ghalia Indonesia

Nugraha, I. (2008). Aplikasi Algoritma Genetik untuk Optimasi Penjadwalan Kegiatan Belajar Mengajar. Jurnal Teknik Informatika, Institut Teknologi Bandung

O'Brien, J. (2005). Pengantar Sistem Informasi: Perspektif Bisnis dan Manajerial. Jakarta: Penerbit Salemba Empat

Obitko, M. (13 September 1998). Introuction to Genetic Algorithm. (Online). Diakses pada tanggal 13 September 2014, pukul 08:37 WIB, dari http://www.obitko.com/tutorials/geneticalgorithms/

Oktavian, D. P. (2010). Menjadi Programmer Jempolan Menggunakan PHP. Yogyakarta: Penerbit Media Kom

Pengertian Dasar Tentang Optimasi. (10 Maret 2015). Diakses dari http://duniaoptimasi.blogspot.com/2011/03/pen gertian-dasar-tentang-optimasi.html? $\mathrm{m}=1$

Pressman, R. S. (2002). Rekayasa Perangkat Lunak Pendekatan Praktisi (Buku Satu). Yogyakarta: Andi

Rifai, U. A. (2011). Pengembangan Aplikasi Penjadwalan Kegiatan dengan Menggunakan Algoritma Genetika. Skripsi S1, Universitas Islam Negeri Syarif Hidayatullah, Jakarta

Sam'ani. (2012). Rancang Bangun Sistem Penjadwalan Perkuliahan dan Ujian Akhir Semester dengan Pendekatan Algoritma Genetika. Tesis S2, Universitas Diponegoro, Semarang

Satriyanto, E. (2009, 16 September). Algoritma Genetika. (Online). Diakses pada tanggal 16 September 2014, pukul 20:29 WIB, dari http://lecturer.eepisits.edu/ kangedi/materi\%20 kuliah/Kecerdasan\%20Buatan/Bab\%207\%20Al goritma\%20Genetika.pdf

Setiawan, E. (2011). KBBI Offline Versi 1.3. KBBI Daring (Edisi Ketiga) diambil dari http://pusatbahasa.kemdiknas.go.id/kbbi/

Sugiyono. (2009). Metode Penelitian Kuantitatif dan Kualitatif. Bandung: C.V. Alfabeta

Sutabri, T. (2004). Analisis Sistem Informasi. Yogyakarta: Andi

Tian, J. (2005). Software Quality Engineering: Testing, Quality Assurance, and Quantifiable Improvement. Wiley-IEEE Computer Society Press

Umar, H. (2005). Metode Penelitian Untuk Skripsi dan Tesis Bisnis. Jakarta: P.T. Gramedia Pustaka Utama

Usman, N. (2002). Konteks Implementasi Berbasis Kurikulum. Jakarta: PT. Raja Grafindo Persada

Yulianto, A. A., I. Gartina, R. Astuti, S., Dewi, S. K. S., W. Witanti. (16 September 2009). Analisis dan Desain Informasi. Politeknik Telkom Bandung. Diakses dari http://courseware.politekniktelkom.ac.id/BUKU
KA/Semester\%203/IS193\%20Analisis\%20Per ancangan\%20Sistem\%20Informasi/Analisis\%20 Perancangan $\% 20$ S.pdf 